\title{
Long-term course of negative symptom subdomains and relationship with outcome in patients with a psychotic disorder
}

Citation for published version (APA):

Stiekema, A. P. M., Islam, M. A., Liemburg, E. J., Castelein, S., van den Heuvel, E. R., van Weeghel, J., Aleman, A., Bruggeman, R., van der Meer, L., \& Genetic Risk and Outcome of Psychosis (GROUP) Investigators (2018). Long-term course of negative symptom subdomains and relationship with outcome in patients with a psychotic disorder. Schizophrenia Research, 193, 173-181.

https://doi.org/10.1016/j.schres.2017.06.024

Document status and date:

Published: 01/03/2018

DOI:

10.1016/j.schres.2017.06.024

Document Version:

Publisher's PDF, also known as Version of record

\section{Document license:}

Taverne

Please check the document version of this publication:

- A submitted manuscript is the version of the article upon submission and before peer-review. There can be important differences between the submitted version and the official published version of record.

People interested in the research are advised to contact the author for the final version of the publication, or visit the DOI to the publisher's website.

- The final author version and the galley proof are versions of the publication after peer review.

- The final published version features the final layout of the paper including the volume, issue and page numbers.

Link to publication

\footnotetext{
General rights rights.

- You may freely distribute the URL identifying the publication in the public portal. please follow below link for the End User Agreement:

www.umlib.nl/taverne-license

Take down policy

If you believe that this document breaches copyright please contact us at:

repository@maastrichtuniversity.nl

providing details and we will investigate your claim.
}

Copyright and moral rights for the publications made accessible in the public portal are retained by the authors and/or other copyright owners and it is a condition of accessing publications that users recognise and abide by the legal requirements associated with these

- Users may download and print one copy of any publication from the public portal for the purpose of private study or research.

- You may not further distribute the material or use it for any profit-making activity or commercial gain

If the publication is distributed under the terms of Article $25 \mathrm{fa}$ of the Dutch Copyright Act, indicated by the "Taverne" license above, 


\title{
Long-term course of negative symptom subdomains and relationship with outcome in patients with a psychotic disorder
}

\author{
Annemarie P.M. Stiekema a,b,*, Md Atiqul Islam c,d,e , Edith J. Liemburg c,d,f,g , Stynke Castelein c,g, \\ Edwin R. van den Heuvel ${ }^{\mathrm{h}}$, Jaap van Weeghel ${ }^{\mathrm{i}, \mathrm{j}}$, André Aleman ${ }^{\mathrm{f}, \mathrm{k}}$, Richard Bruggeman ${ }^{\mathrm{c}, \mathrm{d}}$, \\ Lisette van der Meer ${ }^{\mathrm{a}, \mathrm{c}}$, GROUP-investigators \\ a Department of Rehabilitation, Lentis Psychiatric Institute, Zuidlaren, The Netherlands \\ b School for Mental Health and Neuroscience, Faculty of Health, Medicine and Life Sciences, Maastricht University Medical Centre, Maastricht, The Netherlands \\ c University of Groningen, University Center for Psychiatry, University Medical Center Groningen, Groningen, The Netherlands \\ d University of Groningen, Rob Giel Research Center, University Medical Center Groningen, Groningen, The Netherlands \\ e Department of Statistics, Shahjalal University of Science and Technology, Sylhet 3114, Bangladesh \\ f University of Groningen, Department of Neuroscience, Groningen, University Medical Center Groningen, The Netherlands \\ g Research Department, Lentis Psychiatric Institute, Groningen, The Netherlands \\ h Department of Mathematics and Computer Science, Eindhoven University of Technology, Eindhoven, The Netherlands \\ i Parnassia Group, Dijk en Duin Mental Health Center, Castricum, The Netherlands \\ Department of TRANZO, Tilburg School of Social and Behavioral Sciences, Tilburg University, The Netherlands \\ ${ }^{\mathrm{k}}$ Department of Clinical Psychology and Experimental Psychopathology, University of Groningen, Groningen, The Netherlands
}

\section{A R T I C L E I N F O}

\section{Article history:}

Received 27 January 2017

Received in revised form 14 June 2017

Accepted 14 June 2017

Available online 22 June 2017

\section{Keywords:}

Negative symptoms

Social amotivation

Expressive deficits

Functional outcome

Long-term course

\begin{abstract}
A B S T R A C T
Background: The longitudinal course of the negative symptoms subdomains social amotivation (SA) and expressive deficits (ED) remains largely unknown. We investigated $i$ ) the longitudinal course of SA and ED subdomain scores, $i$ ) whether subgroups based on the course of SA and ED subdomain scores could be identified, iii) whether baseline SA and ED subdomain scores were related to functioning and quality of life six years later and $i v$ ) the longitudinal relationship between subgroups and outcomes.

Methods: Measurements at baseline, three and six years from 1067 patients participating in the Genetic Risk and Outcome of Psychosis (GROUP) project were used. We applied mixed models analysis, regression analysis and trajectory analyses.

Results: SA and ED subdomain scores decreased over time. Within both subdomains, four subgroups were identified: for both SA and ED a steady low course $( \pm 60 \%)$, increased $( \pm 15 \%)$ and decreased course $( \pm 15 \%)$. Within SA only, a higher level decreased course $( \pm 6 \%)$ and within ED only, a course with relatively stable high ED scores $( \pm 6 \%)$ was found. Lower symptom levels at baseline were related to better functioning (SA \& ED) and quality of life (SA) at six years. Overall, low SA and low ED subgroups showed better outcomes than the other subgroups. Conclusion: In many patients the course of negative symptoms is unstable and related to the course of outcome. Patients who do show steady low negative symptom levels (60\%) may complicate the interpretation of treatment evaluation studies, as they may average out possible effects in subgroups with fluctuating symptom levels.
\end{abstract}

(c) 2017 Elsevier B.V. All rights reserved.

\section{Introduction}

Although positive symptoms are usually most dominant in the acute phase of psychotic disorder, negative symptoms are considered to be most disabling, due to their persistent nature and profound relationship with poor functional outcomes (Bobes et al., 2010; Ventura et al., 2009). Despite the growing body of research, both pharmacological and

\footnotetext{
* Corresponding author at: Department of Rehabilitation, Lentis Psychiatric Institute, Zuidlaren, The Netherlands.

E-mail address: annemarie.stiekema@maastrichtuniversity.nl (A.P.M. Stiekema).
}

psychosocial interventions only have a limited effect on reducing negative symptoms (Savill et al., 2014). The heterogeneous nature of negative symptoms makes them difficult to treat. Grouping negative symptoms into two subdomains can diminish this heterogeneity (Foussias et al., 2014b; Messinger et al., 2011). One possibility of grouping symptoms is distinguishing two subdomains on the basis of the Positive and Negative Syndrome Scale (PANSS; Kay et al., 1987): social amotivation (SA) and expressive deficits (ED) (Liemburg et al., 2013; Stiekema et al., 2016). SA encompasses social and emotional withdrawal and reflects diminished interest in or affective commitment to the social environment. ED involves blunted affect, poverty of speech, and motor retardation. The robustness of such subdomains is illustrated by the finding that similar 
subdomains can be grouped based on the Scale for the Assessment of Negative Symptoms (SANS; Andreasen, 1983) even though the composition of both subdomains differs somewhat depending on the instrument that is used to assess symptoms (Foussias et al., 2014a; Liemburg et al., 2013; Stiekema et al., 2016). This difference most importantly concerns the allocation of the apathy item. When the PANSS is used, the factor structure appoints the "apathy item" to the ED subdomain (Liemburg et al., 2013; Stiekema et al., 2016). When the SANS (Andreasen, 1983) is used, the "apathy item" is appointed to SA (Foussias et al., 2014a).

$\mathrm{SA}$ is thought to be the result of a deficit in anticipating on pleasurable events and activities (Buck and Lysaker, 2013; Foussias et al., 2014b). ED reflects a diminished expressive responsiveness that is observed in verbal and non-verbal communication, caused by or related to, neurocognitive deficits (Bell et al., 2013; Ergül and Üçok, 2015; Hartmann-Riemer et al., 2015; Liemburg et al., 2013). There is ample evidence for a strong relationship between SA and global functioning (Fervaha et al., 2014b; Foussias et al., 2011; Rocca et al., 2014). The associations of ED with functioning were found to be less strong (Foussias et al., 2011; Galderisi et al., 2014; Strauss et al., 2013). We recently reported that ED, but not SA, predicted residential living status in a chronic population with psychotic disorders (Stiekema et al., 2016), indicating that ED may in fact be related to daily functioning. However, the extent to which scores on subdomains are consistent over time remains unclear. The few studies that have investigated the longitudinal course of the ED and SA subdomains showed mixed results, varying from long-term stability of both domains (Galderisi et al., 2013), of the expressive but not the amotivation domain (Ergül and Üçok, 2015), and vice versa (Norman et al., 2015).

In the current study, we investigated the longitudinal course of SA and ED subdomain scores. Secondly, we examined whether subgroups with different longitudinal courses of SA and ED could be identified. Thirdly, we investigated whether baseline levels of SA and ED were related to functioning (global functioning, social functioning, independent living, and engagement in work or study) and quality of life six years later. Finally, we assessed the longitudinal relationship between subgroups and functioning and quality of life. Following up on our previous findings, we hypothesized that both subdomains would be related to global functioning and engagement in work or study, that SA would be most strongly related to social functioning and quality of life, while ED would be related to non-independent living status.

\section{Methods}

\subsection{Study design}

We used data from the Genetic Risk and Outcome of Psychosis (GROUP) project, in which outpatients and inpatients with a psychotic disorder between 16 and 50 years were recruited from 36 sites in the Netherlands. Between April 2004 and December 2013, participants were assessed at baseline and three and six years thereafter. Study procedures have been described in detail elsewhere (Korver et al., 2012).

\subsection{Participants}

The GROUP sample consisted of 1119 patients and 586 healthy controls at baseline (Korver et al., 2012). Fifty-three patients were excluded because their diagnosis was missing $(n=4)$, unclear $(n=21)$ or other than primary psychotic $(n=27)$ leading to an inclusion of 1067 patients in the analysis (see Table 1 for demographic characteristics).

\subsection{Assessment}

Psychopathology in the past week was assessed with the Positive and Negative Syndrome Scale (PANSS, Kay et al., 1987). For each patient, SA (sum score of items N2, N4 and G16) and ED (sum score of items N1, N3, N6, G5, G7 and G13) subdomains scores were calculated at baseline
(Liemburg et al., 2013). Global functioning in the past month was measured with the Global Assessment of Functioning Disability scale (GAFD, American Psychiatric Association, 2000)), on an anchored scale from 1 (most severe) to 100 (excellent functioning). Both the PANSS and the GAF were assessed by a trained interviewer (research assistant, psychologist, psychiatrist, nurse or PhD student).

Social functioning at the moment of assessment was measured with the Social Functioning Scale (SFS) (Birchwood et al., 1990), filled out by the participant at three and six years. The SFS score was computed as the mean of the seven subscales scaled scores.

Current living situation, employment and educational activities were assessed at each measurement as part of the demographical information. Independent living (single or with partner or own family vs. living with parents or other family members or sheltered living) and engagement in work or study (work/study vs. no work/study) were also used as functional outcome measures.

Quality of life was assessed with the World Health Organization Quality of Life-BREF (WHO-QOL-BREF, Trompenaars et al., 2005)), a self-report questionnaire based on the past two weeks, including four domains of quality of life: physical health, psychological, social relationships, and environment.

Neurocognition was based on a composite score (mean z-scores) of the Continuous Performance Test, Word Learning Task immediate recall and delayed recall and recognition, and WAIS-III Symbol Substitution, Information, Arithmetic and Block Design. Healthy control subjects were used to obtain age and gender specific z-scores for patients.

\subsection{Statistical analysis}

\subsubsection{Evaluation of missing data}

Baseline characteristics of completers versus non-completers (patients who did not participate in the three and/or six-year measurement) were compared using the Kruskal-Wallis test for continuous variables and Chi-square tests for categorical variables. Multiple imputation was applied to address missing data (due to absenteeism, attrition, or a failure to complete the questionnaire on time), since ignoring missing data may yield biases as it does not differentiate missing at random mechanism (Little and Rubin, 2002) (see S1 for details). For all analyses two-tailed tests, with $\alpha=0.05$ were performed using Statistical Analysis System (SAS), version 9.4 (SAS Institute Inc., 2013).

\subsubsection{Longitudinal course of SA and ED subdomain scores}

The longitudinal course of SA and ED subdomain scores over time was assessed with a linear mixed model applied on imputed data, including only the fixed effect of time as a categorical independent variable. All analyses were conducted for SA subdomain scores and ED subdomain scores separately.

\subsubsection{Identification of subgroups based on $S A$ and ED subdomain scores}

Subgroups within both SA and ED subdomains were identified with group-based trajectory modeling (GBTM), a semi-parametric statistical method for analyzing developmental trajectories (Jones et al., 2001; Niyonkuru et al., 2013) (See S2 for details). Clusters of patients following similar patterns based on the SA or ED subdomain scores will be referred to as SA or ED subgroups, respectively. Differences between the identified subgroups on baseline demographic and clinical characteristics were examined using the Kruskal-Wallis test for continuous variables and Chi-square or Fishers exact tests for categorical variables. Pairwise comparisons were corrected for multiple testing using Bonferroni correction.

2.4.4. Associations between subdomain scores and outcome at six years

To investigate the relationship between baseline SA and ED subdomain scores and functioning and quality of life six years later, multiple linear regression analysis was conducted on six year imputed GAF, SFS and WHO-QOL scores. Logistic regression was applied on 
Table 1

Baseline demographic and clinical characteristics of participants $(n=1067)$

\begin{tabular}{|c|c|c|c|c|c|}
\hline & $\mathrm{N}$ (total sample) & Mean (standard deviation) or percentage & Completers & Non-completers & $p$-Value $\mathrm{e}^{\mathrm{e}}$ \\
\hline \multicolumn{6}{|l|}{ Demographics } \\
\hline Age, years & 1059 & $27.1(7.24)$ & $27.4(7.35)$ & $26.7(7.05)$ & 0.104 \\
\hline Gender, male & 1067 & $77.1 \%$ & $76.2 \%$ & $78.5 \%$ & 0.414 \\
\hline Education $^{\mathrm{a}}$ & 1015 & $4.0(2.06)$ & $4.2(2.00)$ & $3.8(2.11)$ & 0.001 \\
\hline Caucasian & 823 & $79.2 \%$ & $84.3 \%$ & $71.5 \%$ & $<\mathbf{0 . 0 0 1}$ \\
\hline Marital status & 1051 & & & & \\
\hline Not married & 929 & $88.4 \%$ & $88.3 \%$ & $88.5 \%$ & 1.000 \\
\hline Married/living together & 93 & $8.8 \%$ & $9.3 \%$ & $8.1 \%$ & 0.579 \\
\hline Divorced/widowhood & 29 & $2.8 \%$ & $2.4 \%$ & $3.3 \%$ & 0.344 \\
\hline Residential status & 991 & & & & \\
\hline Single or with partner/family & 433 & $43.7 \%$ & $45.4 \%$ & $41.1 \%$ & 0.409 \\
\hline With parent(s) or sheltered living & 494 & $49.8 \%$ & $50.1 \%$ & $49.5 \%$ & 0.791 \\
\hline Other & 64 & $6.5 \%$ & $4.5 \%$ & $9.5 \%$ & 0.002 \\
\hline \multicolumn{6}{|l|}{ Clinical characteristics } \\
\hline Diagnosis & 1067 & & & & \\
\hline Schizophrenia & 722 & $67.7 \%$ & $65.6 \%$ & $70.8 \%$ & 0.083 \\
\hline Schizo-affective disorder & 120 & $11.2 \%$ & $11.9 \%$ & $10.3 \%$ & 0.431 \\
\hline Psychosis NOS & 113 & $10.6 \%$ & $11.9 \%$ & $8.6 \%$ & 0.104 \\
\hline Schizophreniform & 62 & $5.8 \%$ & $6.1 \%$ & $5.4 \%$ & 0.690 \\
\hline Other & 50 & $4.7^{\mathrm{b}} \%$ & $4.6 \%$ & $4.9 \%$ & 0.770 \\
\hline Duration of illness, years & 1011 & $4.2(3.83)$ & 4.5 (4.09) & $3.8(3.33)$ & 0.005 \\
\hline Recent onset psychosis ${ }^{c}$ & 1067 & $32.6 \%$ & $69.5 \%$ & $64.3 \%$ & 0.083 \\
\hline Number of hospitalizations & 895 & 1.9 & $1.9(2.41)$ & $1.9(2.01)$ & 0.540 \\
\hline Number of psychotic episodes & 1041 & 1.7 & $1.8(1.09)$ & $1.7(1.20)$ & 0.115 \\
\hline GAF & 970 & $54.4(16.03)$ & $56.3(15.76)$ & $51.4(16.02)$ & $<\mathbf{0 . 0 0 1}$ \\
\hline SFS total ${ }^{\mathrm{d}}$ & - & - & - & - & - \\
\hline PANSS total & 1014 & $54.9(16.77)$ & $52.95(15.97)$ & $57.81(17.54)$ & $<0.001$ \\
\hline PANSS positive & 1015 & $12.7(5.33)$ & $12.24(5.14)$ & $13.49(5.55)$ & $<0.001$ \\
\hline PANSS negative & 1012 & $14.1(6.01)$ & $13.49(5.67)$ & $14.99(6.40)$ & $<0.001$ \\
\hline PANSS general & 1014 & $28.1(8.40)$ & $27.21(7.98)$ & $29.33(8.86)$ & $<0.001$ \\
\hline PANSS social amotivation & 1001 & $6.2(3.09)$ & $6.0(3.00)$ & $6.5(3.21)$ & 0.025 \\
\hline PANSS expressive deficits & 996 & $10,79(4.76)$ & $10.4(4.49)$ & $11.3(5.10)$ & 0.010 \\
\hline WHO-QOL total & 946 & $88.4(14.82)$ & $89.11(14.66)$ & $87.25(15.04)$ & 0.054 \\
\hline
\end{tabular}

GAF: Global Assessment of Functioning; SFS: Social Functioning Scale; PANSS: Positive and Negative Syndrome Scale; WHO-QoL: World Health Organization Quality of Life.

a Education (Verhage): range 1 (no education), 2 (education but no diploma), 3-5 (school diploma) to 8 (university degree).

b 32 Brief psychotic disorder (2.9\%), 22 delusional disorder (2.1\%), 1 psychotic disorder due to medical condition $(0.1 \%)$.

c First psychotic episode $<2$ years prior to baseline measurement.

d The SFS was only administered at the 3 and 6 year measurements.

e Kruskal-Wallis test were used for continuous variables and Chi-square tests for categorical variables.

living situation and work activities to investigate the relationship. Baseline SA and ED were entered into the first block, gender, duration of illness, positive symptoms (PANSS positive subscale), and neurocognition (composite score) into the second block.

\subsubsection{Longitudinal relationship between SA and ED subdomain scores and outcomes}

Associations between subgroups and continuous outcomes were analyzed with linear mixed models; parameter estimates and their variance components were estimated with restricted maximum likelihood (REML). Associations between subgroups and imputed categorical outcomes were analyzed with generalized linear mixed models (random intercept (patients) mixed model); parameters and their associated standard errors were estimated using an adaptive Gaussian quadrature with 10 quadrature points. All independent variables (including subgroups within subdomains and time as a categorical measure) were included in the statistical model as fixed effects. Gender, duration of illness, positive symptoms, and neurocognition were included in the model to control for these effects. Pooled Type-III tests of fixed effects $p$-values (Li et al., 1991; Rubin, 1987) were used to conclude the marginal effects on different outcomes. Mean differences of SA or ED subgroups were compared and corrected for multiple testing using Bonferroni correction.

\section{Results}

Baseline characteristics are shown in Table 1. Compared to completers, non-completers on average had a significantly shorter duration of illness, lower education levels, lower GAF scores and more severe psychotic symptoms, including higher SA and ED subdomain scores (see Table 1). Supplementary Table 1 shows an overview of missing data. The percentage of patients with missing data at both three and six years follow up was $25.1 \%$ for the SA subdomain scores and $25.5 \%$ for the ED subdomain scores.

\subsection{Longitudinal course of SA and ED subdomain scores}

SA and ED subdomain scores both significantly reduced over time (overall pooled Type-III fixed effect $F_{2,2120}=65.69, p<0.001 ; F_{2,2120}$ $=84.90, p<0.001$ ) (See the overall profile in Fig. 1 ).

\subsection{Identification of subgroups based on SA and ED subdomain scores}

Within each subdomain, four subgroups with a different course of negative symptoms could be identified (see Fig. 1 and Supplementary Table 2). For SA, the majority of the patients (58\%) showed a steady low level of SA symptoms across all time points (low SA subgroup). In $21 \%$ of the patients SA subdomain score started high at study entry and decreased over time (decreased-low SA subgroup). The same pattern but on a higher level was found for $6 \%$ of the patients (decreased-high SA subgroup). Conversely, $15 \%$ of the patients started out with low SA subdomain scores that increased over time (increased SA subgroup) (Fig. 1).

Similarly, for ED the majority of patients (64\%) showed a steady and low ED subdomain score over time (low ED subgroup). In $17 \%$ of the patients a high ED subdomain score at the start decreased over time (decreased ED subgroup). Conversely, 14\% of the patients a low ED 


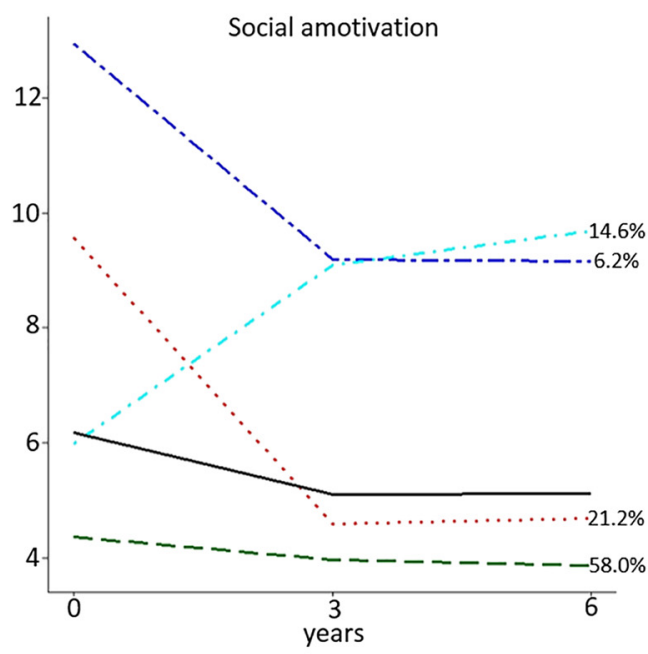

.- decreased-high .. decreased-low * increased — low - overall

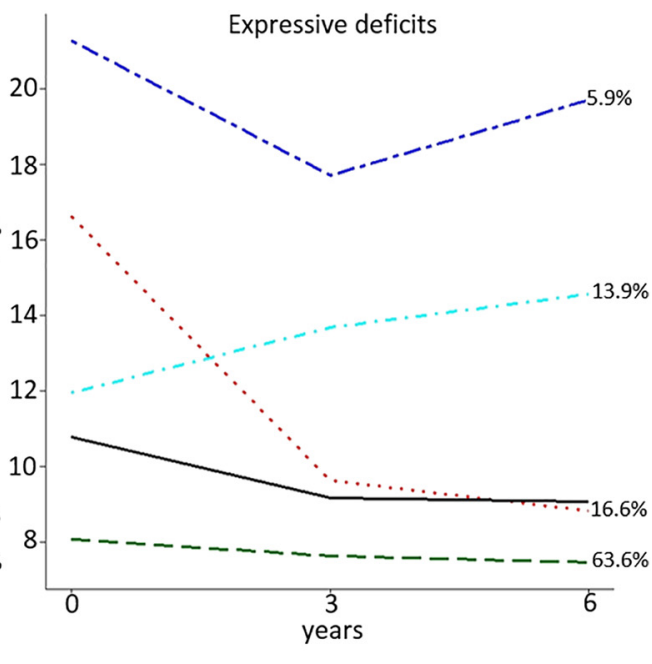

.. high . . decreased . - increased - low - overall

Fig. 1. Subgroups based on the course of SA (left) and ED (right) subdomain scores over a period of 6 years.

subdomain score at the sart increased over time (increased ED subgroup). Finally, in the ED subdomain, and additional small subgroup (6\%) was identified with a steady high ED subdomain score over time (high ED subgroup) (Fig. 1).

Although subgroup differences in baseline characteristics are not all significantly different, a pattern is visible in Table 2 . For example, the low SA and ED subgroups show the highest level of education and the highest percentage of married or living together, the high SA and ED subgroups show the lowest education level and the lowest percentage of married or living together and the other groups show frequencies in between.

\subsection{Associations between subdomain scores and outcome at six years}

Lower baseline SA subdomain scores predicted a higher level of global functioning (GAF; $\beta=-0.73, t=-3.46, p=0.001$ ), social functioning (SFS; $\beta=-0.70, t=-6.30, p<00.001$ ), better quality of life $(\beta=-0.64, t=-3.62, p<0.001)$ and engagement in work or study $(\beta=-0.08, t=-2.18, p=0.03)$ six years later. Lower baseline ED subdomain scores predicted a higher level of global functioning (GAF; $\beta=-0.36, t=-2.09, p=0.04$ ) and social functioning (SFS; $\beta=-0.32, t=-3.40, p=00.002$ ) six years later.

\subsection{Longitudinal relationship between SA and ED subdomain scores and outcomes}

Overall, our data demonstrate a clear pattern distinguishing SA and ED subgroups with low or decreasing subdomain scores from the SA and ED subgroups with high or increasing subdomain scores. The former generally demonstrate an improvement in outcome variables, whereas the latter subgroups show a less favorable course of outcome (see Fig. 2). Looking at the outcome at the individual time points, our most important findings show that within the SA subdomain the low SA subgroup scored higher (better) than the other SA subgroups on the GAF, SFS and the WHOQOL-BREF at all time points. Within the ED subdomain, the low ED subgroup scored higher (better) than the other subgroups at all time points on the GAF and SFS, except for the six-year measurement compared to the decreased ED. Overall, the living situation in the low ED subgroup improved, but patients remained less independent than patients in the other ED subgroups, which was significant at study entry (low ED vs decreased ED) and at 3 years (low ED vs high ED). (See Supplementary Table 3 for details).

Longitudinally, we showed significant differences between subgroups within SA and ED subdomains with regard to outcome
(See Table 3 and Fig. 2). In general, patients with steady low SA or ED subdomain scores, show the most favorable course of outcome. Patients in whom SA and ED scores decrease generally improve over time on all outcome measures. The course of outcome is least favorable for the subgroups with increased SA and ED subdomain scores, who tend to worsen on outcomes, and for the subgroup with steady high ED subdomain scores, who show the lowest outcome scores on all measures except quality of life.

\section{Discussion}

In the current study, we aimed to shed more light on the course of negative symptoms on the subdomains SA and ED as well as the relationship over time with outcome. To this end, we (1) examined and mapped the course of SA and ED over a period of six years. We further disentangled the heterogeneity of negative symptoms by (2) assessing whether subgroups based on the course of SA and ED over time could be distinguished. We then investigated (3) whether SA and ED subdomain scores at baseline were related to functioning and quality of life six years later. Finally, we investigated (4) the course of outcome over six years for the identified subgroups and to what extent this course differed between subgroups.

Most importantly, we demonstrated that though overall symptoms in both the SA and ED subdomain scores decreased over the course of six years, subgroups within the subdomains SA and ED show a less homogenous course of negative symptoms over time. We showed that baseline SA and ED subdomain scores were related to functioning (SA\&ED) and quality of life (SA) six years later. Finally, we demonstrated a differential pattern for outcome over a period of six years for the different subgroups within SA and ED.

\subsection{Longitudinal course and subgroups of SA and ED}

Overall, our findings suggest a decrease of SA and ED subdomain scores over time. According to the literature, improvement of negative symptoms often takes place in the first few years of illness (Eaton et al., 1995; Evensen et al., 2012; Hovington et al., 2012) and an increase in negative symptoms is predominantly found in chronic patients (Chang et al., 2011). By introducing subgroups, we were able to demonstrate a more detailed account of negative symptom development. Though the majority of patients showed a steady low score on the SA subdomain (58\%) and ED subdomain (64\%), approximately one third of the patients either improved or decreased on SA and ED subdomain scores over time. For a small, but significant, 
Table 2

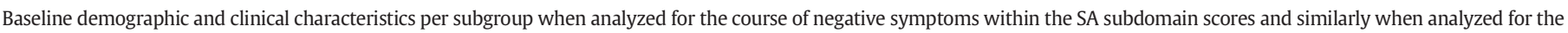
course within the ED subdomain scores ${ }^{\mathrm{a}}$.

\begin{tabular}{|c|c|c|c|c|c|c|c|c|}
\hline & \multicolumn{4}{|c|}{ Subgroups based on the course of SA subdomain scores } & \multicolumn{4}{|c|}{ Subgroups based on the course ED subdomain scores } \\
\hline & $\begin{array}{l}\text { Low } \\
(n=670)\end{array}$ & $\begin{array}{l}\text { Decreased-low } \\
(n=120)\end{array}$ & $\begin{array}{l}\text { Increased } \\
(n=223)\end{array}$ & $\begin{array}{l}\text { Decreased-high } \\
(n=54)\end{array}$ & $\begin{array}{l}\text { Low } \\
(n=715)\end{array}$ & $\begin{array}{l}\text { Decreased } \\
(n=180)\end{array}$ & $\begin{array}{l}\text { Increased } \\
(n=114)\end{array}$ & $\begin{array}{l}\text { High } \\
(n=58)\end{array}$ \\
\hline \multicolumn{9}{|l|}{ Demograhic characteristics } \\
\hline Age, years & $26.9(7.22)^{\#}$ & $26.8(7.16)$ & $28.4(7.50)$ & $28.4(6.95)$ & $27.4^{\#}$ & $25.4(6.43)^{\dagger}$ & $28.5(7.14)^{\ddagger}$ & $26.0(7.70)$ \\
\hline Gender, male & $73.3^{+}$ & 82.1 & 81.7 & 94.4 & $75.0^{\ddagger}$ & 82.2 & 76.3 & 89.7 \\
\hline Education & $4.2(2.03)^{\ddagger}$ & $3.8(2.11)$ & $3.7(2.01)$ & $3.4(1.95)$ & $4.2^{*}$ & $3.7(2.04)$ & $3.7(2.03)$ & $3.4(2.10)$ \\
\hline Caucasian & $82.1^{\dagger}$ & 77.4 & 70.1 & 71.7 & $80.3^{\ddagger}$ & 80.1 & 77.5 & 66.1 \\
\hline \multicolumn{9}{|l|}{ Marital status } \\
\hline Not married & 86.6 & 90.0 & 92.4 & 94.4 & $86.6^{\#}$ & 82.2 & 87.6 & 94.8 \\
\hline Married/living together & 10.0 & 8.1 & 6.8 & 1.9 & 10.0 & 17.8 & 10.6 & 3.4 \\
\hline Divorced/widowhood & 3.3 & 1.8 & 0.8 & 3.7 & 3.4 & 1.1 & 1.8 & 1.7 \\
\hline \multicolumn{9}{|l|}{ Residential status } \\
\hline Single & 33.9 & 32.4 & 34.5 & 34.6 & 36.4 & 27.5 & 32.1 & 24.1 \\
\hline With parent(s) & 39.7 & 39.1 & 40.9 & 42.3 & 37.7 & 43.9 & 42.5 & 48.1 \\
\hline With partner/family & 11.7 & 8.2 & 7.3 & 1.9 & $12.0^{\#}$ & 5.3 & 8.5 & 3.7 \\
\hline Sheltered living & 8.4 & 13.0 & 11.8 & 13.5 & 8.6 & 11.7 & 12.3 & 16.7 \\
\hline Other & 6.3 & 7.2 & 5.5 & 7.7 & $5.3^{\#}$ & 11.7 & 4.7 & 7.4 \\
\hline \multicolumn{9}{|l|}{ Clinical characteristics } \\
\hline \multicolumn{9}{|l|}{ Diagnosis } \\
\hline Schizophrenia & $61.6^{*}$ & 74.9 & 80.8 & 83.3 & $62.8^{*}$ & 73.9 & 79.8 & 84.5 \\
\hline Schizo-affective disorder & 12.5 & 10.3 & 5.8 & 11.1 & 13.0 & 7.8 & 7.9 & 6.9 \\
\hline Psychosis NOS & $12.5^{\ddagger}$ & 10.3 & 5.0 & - & 11.7 & 10.6 & 6.1 & 5.2 \\
\hline Schizophreniform & $7.0^{\#}$ & 2.2 & 5.8 & 5.6 & 6.0 & 5.6 & 6.1 & 3.4 \\
\hline Other & 6.3 & 2.3 & 2.5 & - & $6.5^{\dagger}$ & 2.1 & - & - \\
\hline Duration of illness, years & $4.2(3.82)$ & $3.9(3.23)$ & $4.7(4.57)$ & $5.1(4.27)$ & 4.3 & $3.8(3.37)$ & $4.5(3.90)$ & $4.1(3.79)$ \\
\hline Recent onset psychosis & 32.5 & 31.8 & 35.8 & 29.6 & 31.9 & 36.1 & 33.3 & 29.3 \\
\hline Number of hospitalizations & $1.7(1.92)$ & $2.1(2.72)$ & $2.2(3.00)$ & $2.0(2.21)$ & 1.8 & $2.2(3.21)$ & $1.8(1.53)$ & $1.9(2.32)$ \\
\hline Number of psychotic episodes & $1.8(1.16)$ & $1.63(1.07)$ & $1.6(1.03)$ & $1.8(1.33)$ & 1.8 & $1.7(1.07)$ & $1.6(0.86)$ & $1.7(1.24)$ \\
\hline Chlorpromazine equivalent total $^{\mathrm{C}}$ & $\begin{array}{l}322.8 \\
(283.25)\end{array}$ & $359.9(342.03)$ & $\begin{array}{l}356.7 \\
(275.86)\end{array}$ & $342.2(280.65)$ & $\begin{array}{l}313.3 \\
(291.64)^{\ddagger}\end{array}$ & $\begin{array}{l}383.2 \\
(326.59)\end{array}$ & $\begin{array}{l}356.9 \\
(278.21)\end{array}$ & $\begin{array}{l}420.4 \\
(241.57)\end{array}$ \\
\hline $\begin{array}{l}\text { Chlorpromazine equivalent of typical } \\
\mathrm{APS}^{\mathrm{b}}\end{array}$ & $\begin{array}{l}120.3 \\
(349.82)\end{array}$ & $191.0(395.20)$ & $\begin{array}{l}137.1 \\
(163.38)\end{array}$ & $257.7(409.05)$ & $\begin{array}{l}140.1 \\
(395.46)^{\ddagger}\end{array}$ & $\begin{array}{l}148.1 \\
(256.84)\end{array}$ & $97.0(135.71)$ & $\begin{array}{l}246.0 \\
(145.46)\end{array}$ \\
\hline $\begin{array}{l}\text { Chlorpromazine equivalent of atypical } \\
\text { APs }^{\text {b }}\end{array}$ & $\begin{array}{l}319.8 \\
(263.66)\end{array}$ & $344.9(275.42)$ & $\begin{array}{l}365.0 \\
(279.58)\end{array}$ & $\begin{array}{l}316.75 \\
(244.90)\end{array}$ & $\begin{array}{l}305.1 \\
(251.83)^{\ddagger}\end{array}$ & $\begin{array}{l}378.9 \\
(312.87)\end{array}$ & $\begin{array}{l}362.6 \\
(278.05)\end{array}$ & $\begin{array}{l}434.2 \\
(227.81)\end{array}$ \\
\hline SA scores & $4.4(1.48)^{*}$ & $9.6(1.57)^{*}$ & $6.0(1.83)^{*}$ & $12.9(2.26)^{*}$ & $5.2(2.57)^{*}$ & $8.5(2.67)^{\dagger}$ & $6.7(2.68)^{*}$ & $10.0(3.64)$ \\
\hline ED scores & $9.1(3.61)^{*}$ & $13.7(4.84)^{*}$ & $11.6(4.30)$ & $16.7(5.87)$ & $8.1(2.12)^{*}$ & $16.6(2.41)^{\dagger}$ & $12.0(2.65)^{*}$ & $21.3(3.39)$ \\
\hline GAF & $58.7(16.41)^{*}$ & $47.1(12.16)^{\ddagger}$ & $51.1(12.95)^{*}$ & $40.4(9.63)^{*}$ & $58.2(15.69)^{*}$ & $46.1(13.18)$ & $51.0(14.25)^{\ddagger}$ & $40.6(12.39)$ \\
\hline PANSS total & $47.8(12.98)^{*}$ & $67.5(14.90)^{*}$ & $57.6(12.7)^{*}$ & $78.6(16.85)^{*}$ & $48.6(13.57)^{*}$ & $68.4(14.11)^{\dagger}$ & $58.5(12.44)^{\ddagger}$ & $79.1(16.69)$ \\
\hline PANSS positive & $11.6(4.61)^{*}$ & $14.8(6.08)$ & $13.3(4.93)$ & $16.3(6.47)$ & $12.1(5.17)^{*}$ & $14.0(5.68)$ & $13.4(4.69)$ & $15.5(5.7)$ \\
\hline PANSS negative & $11.2(4.10)^{*}$ & $19.2(4.98)^{*}$ & $14.9(4.67)^{*}$ & $24.0(5.80)^{*}$ & $11.1(3.82)^{*}$ & $20.5(3.95)^{\dagger}$ & $15.7(4.09)^{\ddagger}$ & $25.2(5.66)$ \\
\hline PANSS general & $25.0(6.86)^{*}$ & $33.47(8.08)^{\dagger}$ & $29.4(6.73)^{*}$ & $38.2(9.14)$ & $25.4(6.97)^{*}$ & $33.9(8.33)^{\dagger}$ & $29.5(6.61)^{\ddagger}$ & $38.4(9.05)$ \\
\hline WHO-QOL-BREF & $91.6(14.50)^{*}$ & $83.7(13.92)$ & $84.0(13.0)$ & $78.9(14.45)$ & $90.2(15.15)^{*}$ & $85.5(13.53)$ & $84.1(12.58)$ & $84.1(14.97)$ \\
\hline Neurocognition & $-0.50(0.61)^{\dagger}$ & $-0.64(0.64)$ & $-0.55(0.69)$ & $-0.65(0.72)$ & $-0.47(0.58)^{*}$ & $-0.74(0.66)$ & $-0.67(0.70)$ & $-0.73(0.62)$ \\
\hline
\end{tabular}

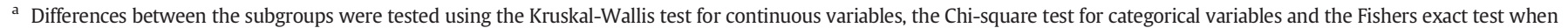

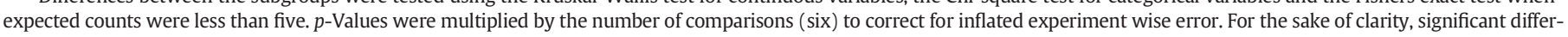
ences between two groups are indicated only in the first column of the groups.

b AP = antipsychotic agents; typical APs: benperidol, bromperidol, chlorprothixene, clotiapine, fluphenazine, flupentixol, haloperidol, levomepromazine, penfluridol, perphenazine, periciazine, pimozide, pipamperon, sulpiride, zuclopenthixol, atypical APs: amisulpride, aripiprazole, clozapine, olanzapine, quetiapine, risperidone.

c Dose equivalents of chlorpromazine were evaluated using the methods of (Gardner et al., 2010).

* Statistically significant difference compared to all other groups within the subdomain at $\alpha=0.05$.

\# Statistically significant difference compared to decreased ( - low) group within the subdomain at $\alpha=0.05$.

$\dagger$ Statistically significant difference compared to increased group within the subdomain at $\alpha=0.05$.

$\doteqdot$ Statistically significant difference compared to (decreased-)high group within the subdomain at $\alpha=0.05$.

group of patients (6\%) symptoms in the ED subdomain remained high over time (high ED subgroup), which was not the case for SA. This supports previous suggestions that symptoms in the ED subdomain may be more persistent (Ergül and Üçok, 2015; Liemburg et al., 2013). Although the subgroups did not differ with regard to the mean duration of illness, it seemed that the decrease and increase of negative symptoms took place mainly in the first three years of the study. This suggests that the variability in symptom level is most prominent within the first years of the illness and may diminish with a longer duration of illness. Moreover, the finding that negative symptom scores (either SA or ED) in a third of the patients either increased or decreased over time, suggests that when these groups are bundled into larger groups changes in negative symptoms over time may be averaged out and thus become invisible. This is important, as these groups may require different treatment approaches.

\subsection{Associations with outcome}

In general, the course of outcomes is in line with previous research that shows that higher severity of negative symptoms is related to more severe functional disabilities (Herbener and Harrow, 2004; Milev et al., 2005). Overall, lower baseline scores on SA or ED subdomains predicted better outcomes six years later. When the subdomains are further disentangled and grouped into subgroups within SA and ED, we demonstrated that people in the lower symptom subgroups generally showed the best outcomes across six years and people in the high SA and ED subgroups the worst outcome. For people in subgroups showing either an increase or decrease in negative symptoms, this was accompanied by a decrease or increase in functioning, respectively.

Our findings support and expand the existing evidence for the robust relationship of SA with functioning and quality of life (Fervaha 

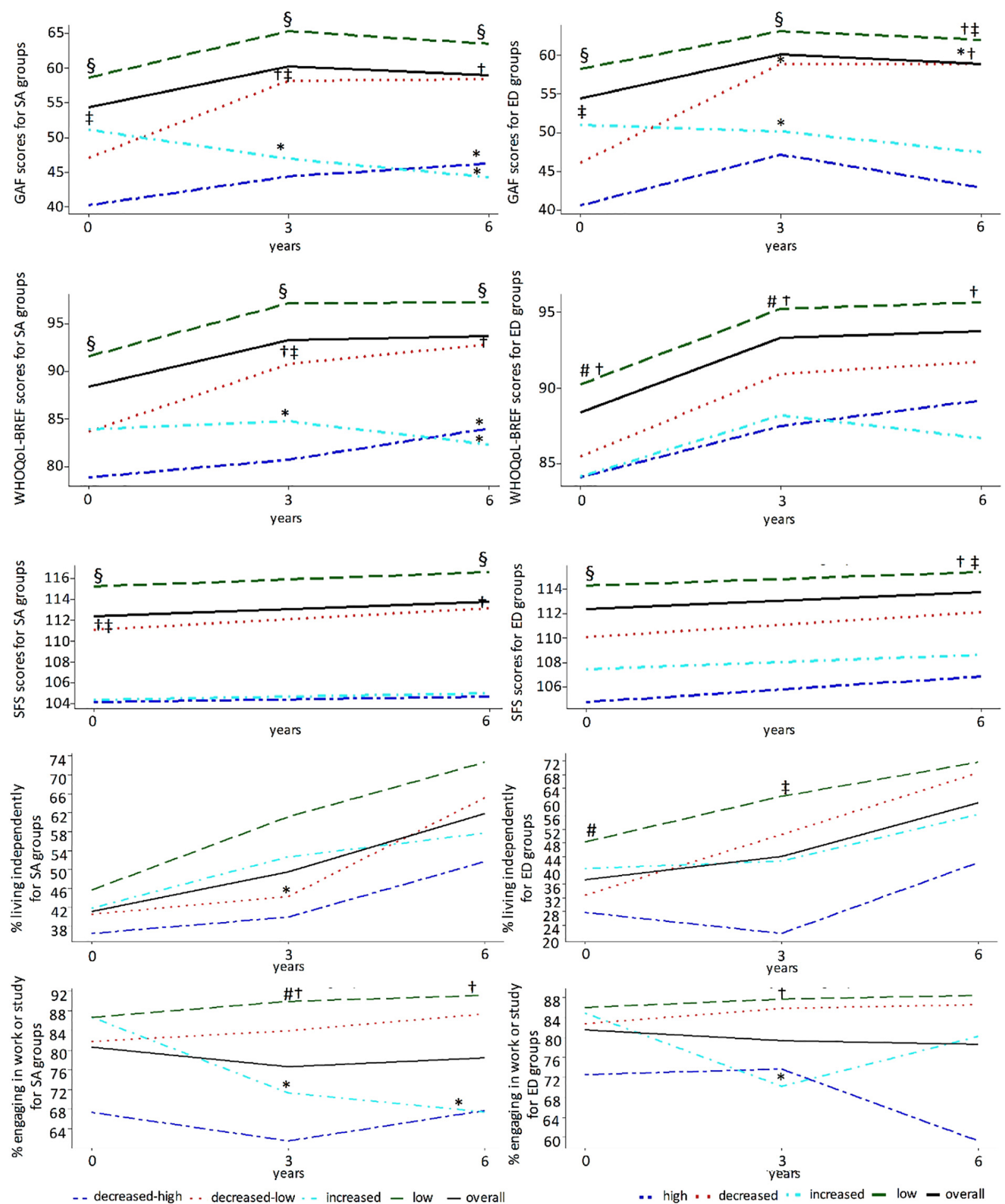

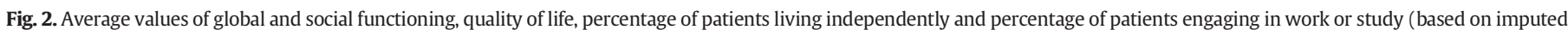

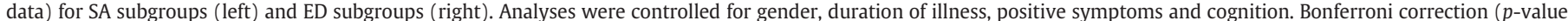

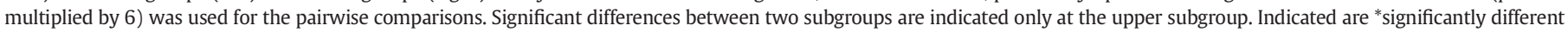

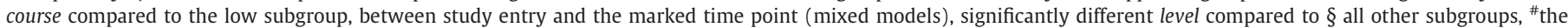
decreased(-low) group, the increased subgroup and $\ddagger$ the (decreased-)high subgroup at the marked time point (pairwise comparisons).

et al., 2014a, 2014b; Messinger et al., 2011; Strauss et al., 2013), and are also in line with our previous study in which higher ED was associated with global functioning in chronic patients (Stiekema et al., 2016). While baseline ED did not predict future living status or engagement in work or study activities, there were some significant differences in course over time and the level of symptoms at each timepoint between the subgroups. Our results indicate that SA is an important treatment target for improving functioning and well-being, but they also point out the importance of ED, in contrast to previous studies. Importantly, not only did we demonstrate that different subgroups within SA and ED can be distinguished, we also demonstrated that these subgroups have different outcomes over the course of six years. 
Table 3

Pooled parameter estimates of mixed models analyses adjusted for gender, duration of illness, neurocognition and positive symptoms ${ }^{\mathrm{a}}$.

\begin{tabular}{|c|c|c|c|c|c|c|c|c|c|c|c|c|}
\hline & \multicolumn{4}{|c|}{ Living situation } & \multicolumn{4}{|c|}{ Work/study } & \multicolumn{4}{|l|}{ GAF } \\
\hline & B & SE & $95 \% \mathrm{CI}$ & $p$-Value & B & SE & $95 \% \mathrm{CI}$ & $p$-Value & B & SE & $95 \% \mathrm{CI}$ & $p$-Value \\
\hline \multicolumn{13}{|l|}{ Social amotivation (SA) } \\
\hline Intercept & 0.37 & 0.32 & $-0.27 ; 1.01$ & 0.253 & 3.25 & 0.27 & $2.71 ; 3.79$ & $<0.001$ & 74.28 & 1.04 & $72.24 ; 76.32$ & $<\mathbf{0 . 0 0 1}$ \\
\hline Decreased-high SA & -0.57 & 0.61 & $-1.76 ; 0.62$ & 0.351 & -0.92 & 0.40 & $-1.71 ;-0.14$ & 0.021 & -11.92 & 1.97 & $-15.78 ;-8.07$ & $<\mathbf{0 . 0 0 1}$ \\
\hline Decreased-low SA & -0.04 & 0.33 & $-0.68 ; 0.60$ & 0.901 & -0.16 & 0.26 & $-0.66 ; 0.35$ & 0.545 & -7.24 & 1.09 & $-9.38 ;-5.10$ & $<0.001$ \\
\hline Increased SA & -0.21 & 0.42 & $-1.04 ; 0.62$ & 0.620 & 0.06 & 0.35 & $-0.63 ; 0.75$ & 0.864 & -5.34 & 1.38 & $-8.04 ;-2.64$ & $<0.001$ \\
\hline Time: 3 years & 0.98 & 0.20 & $0.59 ; 1.37$ & $<0.001$ & 0.11 & 0.23 & $-0.36 ; 0.58$ & 0.644 & 4.03 & 0.73 & $2.60 ; 5.48$ & $<0.001$ \\
\hline Time: 6 years & 2.11 & 0.30 & $1.50 ; 2.72$ & $<0.001$ & 0.23 & 0.20 & $-0.17 ; 0.62$ & 0.256 & 2.80 & 0.72 & $1.38 ; 4.22$ & $<0.001$ \\
\hline Decreased-high $\mathrm{SA} * 3$ years & -1.04 & 0.68 & $-2.37 ; 0.30$ & 0.128 & -0.40 & 0.56 & $-1.51 ; 0.72$ & 0.480 & -0.58 & 2.53 & $-5.58 ; 4.43$ & 0.821 \\
\hline Decreased-high $S A * 6$ years & -0.49 & 0.98 & $-2.50 ; 1.51$ & 0.617 & -0.21 & 0.57 & $-1.34 ; 0.91$ & 0.708 & 2.19 & 2.90 & $-3.63 ; 8.02$ & 0.453 \\
\hline Decreased-low $\mathrm{SA} * 3$ years & -0.73 & 0.35 & $-1.41 ;-0.04$ & 0.039 & -0.37 & 0.43 & $-1.23 ; 0.49$ & 0.388 & 1.39 & 1.43 & $-1.44 ; 4.21$ & 0.332 \\
\hline Decreased-high $\mathrm{SA} * 6$ years & -0.48 & 0.44 & $-1.36 ; 0.40$ & 0.280 & -0.24 & 0.36 & $-0.95 ; 0.47$ & 0.509 & 3.12 & 1.37 & $0.41 ; 5.82$ & 0.024 \\
\hline Increased $\mathrm{SA} * 3$ years & -0.09 & 0.46 & $-0.98 ; 0.81$ & 0.851 & -1.11 & 0.44 & $-1.97 ;-0.26$ & 0.011 & -7.42 & 1.66 & $-10.68 ;-4.17$ & $<\mathbf{0 . 0 0 1}$ \\
\hline Increased $S A * 6$ years & -0.63 & 0.53 & $-1.68 ; 0.41$ & 0.231 & -1.33 & 0.42 & $-2.16 ;-0.50$ & 0.002 & -5.65 & 1.79 & $-9.20 ;-2.10$ & 0.002 \\
\hline \multicolumn{13}{|l|}{ Expressive deficits (ED) } \\
\hline Intercept & 0.52 & 0.32 & $-0.11 ; 1.15$ & 0.107 & 3.40 & 0.28 & $2.86 ; 3.95$ & $<0.001$ & 75.34 & 1.07 & $73.24 ; 77.43$ & $<0.001$ \\
\hline High ED & -1.17 & 0.59 & $-2.32 ;-0.03$ & 0.045 & -0.60 & 0.41 & $-1.42 ; 0.21$ & 0.147 & -11.66 & 1.90 & $-15.38 ;-7.93$ & $<0.001$ \\
\hline Decreased ED & -0.94 & 0.35 & $-1.64 ;-0.25$ & 0.008 & -0.14 & 0.28 & $-0.69 ; 0.41$ & 0.616 & -8.46 & 1.19 & $-10.80 ;-6.11$ & $<0.001$ \\
\hline Increased ED & -0.54 & 0.43 & $-1.38 ; 0.30$ & 0.204 & 0.05 & 0.34 & $-0.61 ; 0.71$ & 0.883 & -4.85 & 1.43 & $-7.64 ;-2.05$ & $<0.001$ \\
\hline Time: 3 years & 0.85 & 0.18 & $0.49 ; 1.21$ & $<0.001$ & -0.03 & 0.21 & $-0.45 ; 0.39$ & 0.896 & 2.89 & 0.68 & $1.55 ; 4.22$ & $<0.001$ \\
\hline Time: 6 years & 1.88 & 0.28 & $1.29 ; 2.47$ & $<0.001$ & 0.02 & 0.21 & $-0.41 ; 0.45$ & 0.913 & 1.90 & 0.78 & $0.35 ; 3.45$ & 0.018 \\
\hline High ED $* 3$ years & -0.90 & 0.67 & $-2.23 ; 0.42$ & 0.179 & -0.15 & 0.64 & $-1.43 ; 1.14$ & 0.820 & 1.99 & 2.58 & $-3.14 ; 7.11$ & 0.443 \\
\hline High ED $* 6$ years & -0.53 & 0.94 & $-2.48 ; 1.42$ & 0.579 & -0.34 & 0.53 & $-1.38 ; 0.69$ & 0.515 & 3.14 & 2.91 & $-2.73 ; 9.01$ & 0.287 \\
\hline Decreased ED $* 3$ years & 0.14 & 0.38 & $-0.60 ; 0.88$ & 0.708 & -0.09 & 0.39 & $-0.86 ; 0.67$ & 0.811 & 4.52 & 1.44 & $1.69 ; 7.36$ & 0.002 \\
\hline Decreased ED $* 6$ years & 0.56 & 0.42 & $-0.26 ; 1.38$ & 0.178 & 0.05 & 0.38 & $-0.70 ; 0.81$ & 0.895 & 6.37 & 1.85 & $2.62 ; 10.12$ & 0.002 \\
\hline Increased $\mathrm{ED} * 3$ years & -0.50 & 0.46 & $-1.41 ; 0.40$ & 0.276 & -0.94 & 0.42 & $-1.77 ;-0.11$ & 0.027 & -3.62 & 1.74 & $-7.05 ;-0.19$ & 0.039 \\
\hline Increased $\mathrm{ED} * 6$ years & -0.37 & 0.48 & $-1.32 ; 0.57$ & 0.439 & -0.42 & 0.51 & $-1.426 ; 0.59$ & 0.413 & -2.51 & 2.02 & $-6.55 ; 1.52$ & 0.217 \\
\hline
\end{tabular}

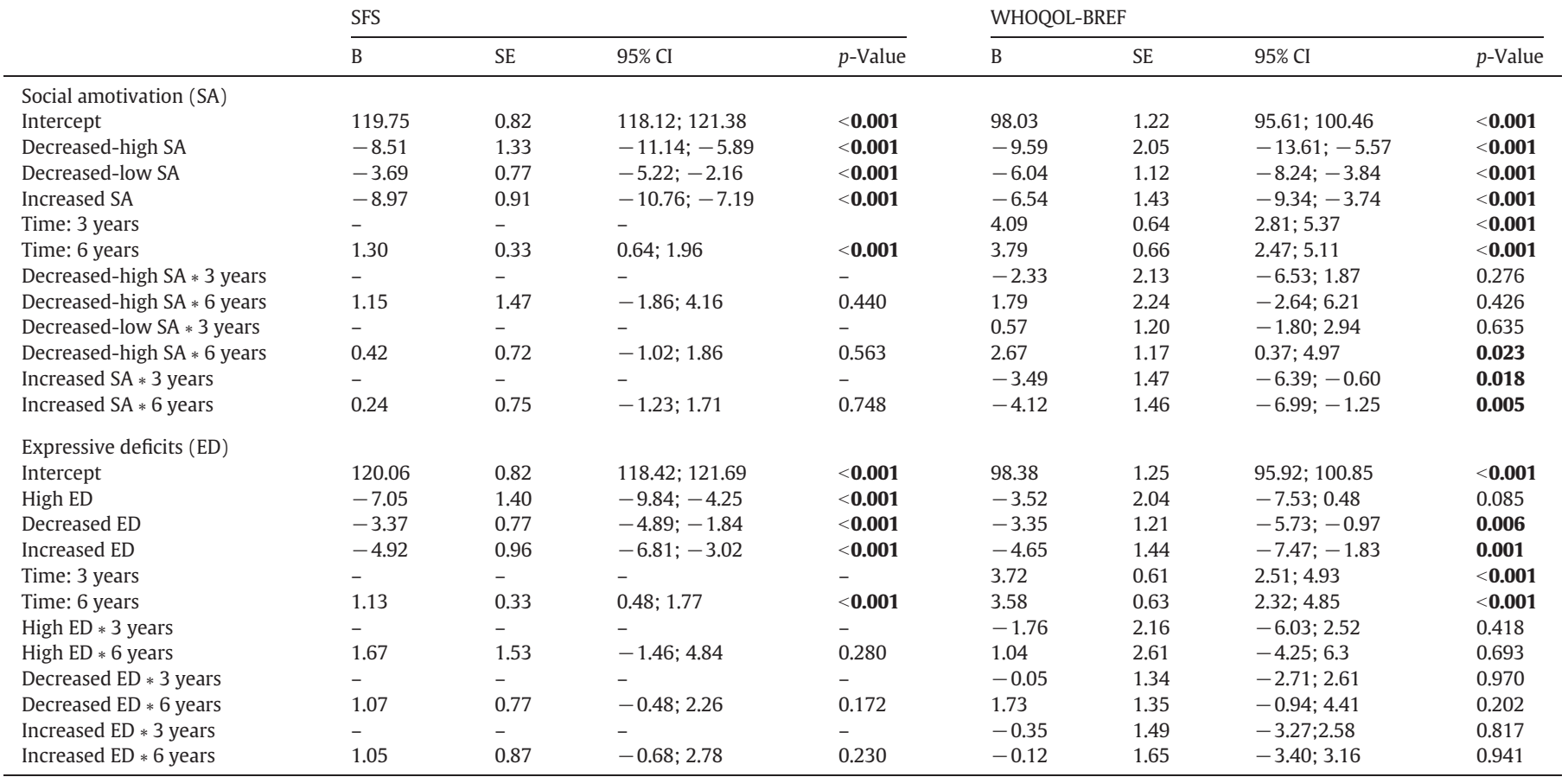

${ }^{a}$ Reference category for SA is the low SA group, reference category for ED is low ED group. Reference category for time is baseline expect for the SFS. where the three-year measurement was the reference category in the absence of a baseline measurement.

\subsection{Implications}

Of the included patients in this study, about half could be classified in both the low SA and low ED subgroup. Thus, for these patients this leaves limited room (and need) for improvement in negative symptoms. This poses a problem for treatment development, as it causes an increased risk of false negative findings of treatment trials aimed at improving negative symptoms (and accompanied improvement in functioning); possibly improvement of the other $48 \%$ of the patients for whom improvement is possible and necessary is masked as the steady low subgroup may average out effects for the other subgroups. This is clearly visible in Figs. 1 and 2, where the low subgroups show the same pattern as the overall group but at a slightly lower level of symptoms and better level of outcomes. The finding that some of the courses of outcomes that appear visibly different were not significant (such as the differences in living situation within ED) could indicate that other factors (such as positive symptoms and neurocognition) are important for the level and course of the outcomes as well, but it could also be due to reduced power of subgroup analysis.

The few pharmacological studies to date do not yet provide enough information for a firm conclusion about selective responsiveness to treatment (Azorin et al., 2014; Kirkpatrick, 2014). Overall, there is only 
a small number of studies investigating psychosocial interventions with negative symptoms as a primary outcome (Elis et al., 2013), and the differential effects on the subdomains are unclear. SA has been related to the deficits in anticipatory pleasure (Buck and Lysaker, 2013; Foussias et al., 2014b) which may make cognitive behavioral therapy a suitable intervention to address defeatists beliefs (Staring et al., 2013). ED has been linked to cognitive deficits (Bell et al., 2013; Ergül and Üçok, 2015; Hartmann-Riemer et al., 2015; Liemburg et al., 2013), which may lead treatment development in the direction of restorative and/or compensatory cognitive rehabilitation interventions. However, the significant relation of ED with global functioning while controlling for cognition indicates that cognition cannot fully explain this association. Possibly, interventions targeting expressive skills such as Social Skills Training (Bellack et al., 2004; Turner et al., 2014) could improve ED.

\subsection{Strengths, limitations and future directions}

Strengths of this study are the large sample size, the longitudinal nature and the used methodology. Several limitations should also be mentioned. We cannot infer causality from this observational study and we do not know whether changes in negative symptoms are due to relief of secondary negative symptoms. Although positive symptoms were included as a confounder in this study, other factors may have caused secondary negative symptoms for which we were unable to control. This may have influenced the observed patterns of the subgroups over time, and treatment for patients with secondary negative symptoms which require a different approach than the suggested treatment strategies described above (Carpenter et al., 1985). Also, the current results are most applicable for those with predominant SA or ED (Strauss et al., 2013). The relationship between ED and these aspects of functioning should be further elucidated in future research, as our results may have been affected by a conservative method to correct for multiple comparisons and possible power issues, because the high ED subgroup was very small. Further, due to the rather large 3-year intervals capturing short term changes and fluctuations is not possible with the current data. Furthermore, measures for level of functioning and symptoms varied in time prior to assessment, which may result in different conclusions with respect to levels of functioning. In addition, there is a risk of selection bias introduced by the relatively demanding protocol of the GROUP study (Korver et al., 2012). Also, self-reported functioning can differ from clinician-reported functioning, possibly due to limited awareness of functional deficits (Bowie et al., 2007; Durand et al., 2015; Gould et al., 2015). However, assessment of functioning with the GAF was interviewed-based and living situation or engagement in work or study is less prone to bias.

Future research should investigate possible causal mechanisms for the variability in the subdomain levels over time, e.g. whether improvement in negative symptoms facilitates improvements in outcome or vice versa (Álvarez-Jiménez et al., 2012) and whether the subgroups differ with regard to the care they (have) receive(d). A focus on persistent or predominant negative symptoms, taking causes of secondary negative symptoms into account, may help in better determining possible treatment strategies, especially for those with the most severe levels of negative symptoms (Buchanan, 2007; Rabinowitz et al., 2013). For those with co-occurring SA and ED, research into the influence of combinations of SA and ED subgroups is needed, but this was beyond the scope of our study. Research on more specific diagnostic groups could be of value as well, since the low SA and low ED subgroup included significantly fewer patients with schizophrenia.

In summary, our results show that there is a considerable heterogeneity in the course of the subdomains and that the course of the subdomains is related to outcome. Research on treatments for negative symptoms could benefit from distinguishing subgroups within SA and ED to prevent a possible treatment effect to be masked by those steady low levels of symptoms.

\section{Contributors}

APMS, AMdI, LvdM and RB designed the study. APMS, AMdI and EvdH undertook the statistical analyses. APMS an AMdI wrote the first draft of the manuscript. All authors contributed to and have approved the final manuscript.

\section{Conflict of interest}

None.

\section{Role of funding source}

The GROUP study is funded by the Geestkracht program of the Dutch Health Research Council (ZON-MW, grant number 10-000-1001), and matching funds from participating pharmaceutical companies (Lundbeck, AstraZeneca, Eli Lilly, Janssen Cilag) and universities and mental health care organizations (Amsterdam: Academic Psychiatric Centre of the Academic Medical Center and the mental health institutions: GGZ Ingeest, Arkin, Dijk \& Duin, GGZ Rivierduinen, Erasmus Medical Centre, GGZ Noord Holland Noord. Maastricht: Maastricht University Medical Centre and the mental health institutions: GGZ Eindhoven \& de kempen, GGZ Breburg, GGZ Oost-Brabant, Vincent van Gogh voor Geestelijke Gezondheid, Mondriaan Zorggroep, Prins Clauscentrum Sittard, RIAGG Roermond, Universitair Centrum Sint-Jozef Kortenberg, CAPRI University of Antwerp, PC Ziekeren Sint-Truiden, PZ Sancta Maria Sint-Truiden, GGZ Overpelt, OPZ Rekem. Groningen: University Medical Center Groningen and the mental health institutions: Lentis Mental Health Care, GGZ Friesland, GGZ Drenthe, Dimence, Mediant, GGNet Warnsveld, Yulius Dordrecht and Parnassia Psychiatric Institute, The Hague. Utrecht: University Medical Center Utrecht and the mental health institutions Altrecht, GGZ Centraal, Riagg Amersfoort and Delta. Author AA was supported by a VICI grant (no. 453-11-004) from the Netherlands Organization for Scientific Research.

\section{Acknowledgments}

We are grateful for the generosity of time and effort by the patients and their families, healthy subjects, and all researchers who made the GROUP project possible.

\section{Appendix A. Supplementary data}

Supplementary data to this article can be found online at http://dx. doi.org/10.1016/j.schres.2017.06.024.

\section{References}

Álvarez-Jiménez, M., Gleeson, J.F., Henry, L.P., Harrigan, S.M., Harris, M.G., Killackey, E., Bendall, S., Amminger, G.P., Yung, A.R., Herrman, H., Jackson, H.J., McGorry, P.D. 2012. Road to full recovery: longitudinal relationship between symptomatic remission and psychosocial recovery in first-episode psychosis over 7.5 years. Psychol. Med. 42, 595-606.

American Psychiatric Association, 2000. Diagnostic and Statistical Manual of Mental Health Disorders. 4th ed. (Washington DC).

Andreasen, N.C., 1983. Scale for the Assessment of Negative Symptoms (SANS). University of Iowa, Iowa City.

Azorin, J.-M., Belzeaux, R., Adida, M., Hospital, S.M., Marguerite, B. Sainte, 2014. Negative symptoms in schizophrenia: where we have been and where we are heading. CNS Neurosci. Ther. 20, 801-808.

Bell, M.D., Corbera, S., Johannesen, J.K., Fiszdon, J.M., Wexler, B.E., 2013. Social cognitive impairments and negative symptoms in schizophrenia: are there subtypes with distinct functional correlates? Schizophr. Bull. 39, 186-196.

Bellack, A.S., Mueser, K.T., Gingerich, S., Agresta, J., 2004. Social Skills Training for Schizophrenia: A Step-by-step Guide. 2nd ed. Guilford Press, New York.

Birchwood, M., Smith, J., Cochrane, R., Wetton, S., Copestake, S., 1990. The social functioning scale. The development and validation of a new scale of social adjustment for use in family intervention programmes with schizophrenic patients. Br. J. Psychiatry 157: 653-859. http://dx.doi.org/10.1192/bjp.157.6.853.

Bobes, J., Arango, C., Garcia-Garcia, M., Rejas, J., 2010. Prevalence of negative symptoms in outpatients with schizophrenia spectrum disorders treated with antipsychotics in routine clinical practice: findings from the CLAMORS study. J. Clin. Psychiatry 71, 280-286.

Bowie, C.R., Twamley, E.W., Anderson, H., Halpern, B., Patterson, T.L., Harvey, P.D., 2007. Self-assessment of functional status in schizophrenia. J. Psychiatr. Res. 41: 1012-1018. http://dx.doi.org/10.1016/j.jpsychires.2006.08.003.

Buchanan, R.W., 2007. Persistent negative symptoms in schizophrenia: an overview. Schizophr. Bull. 33, 1013-1022.

Buck, B., Lysaker, P.H., 2013. Consummatory and anticipatory anhedonia in schizophrenia: stability, and associations with emotional distress and social function over six months. Psychiatry Res. 205, 30-35.

Carpenter, W., Heinrichs, D., Alphs, L., 1985. Treatment of negative symptoms. Schizophr Bull. 11, 440-452.

Chang, W.C., Hui, C.L.M., Tang, J.Y.M., Wong, G.H.Y., Lam, M.M.L., Chan, S.K.W., Chen, E.Y.H., 2011. Persistent negative symptoms in first-episode schizophrenia: a prospective three-year follow-up study. Schizophr. Res. 133, 22-28.

Durand, D., Strassnig, M., Sabbag, S., Gould, F., Twamley, E.W., Patterson, T.L., Harvey, P.D., 2015. Factors influencing self-assessment of cognition and functioning in schizophrenia: implications for treatment studies. Eur. Neuropsychopharmacol. 25:185-191. http://dx.doi.org/10.1016/j.euroneuro.2014.07.008.

Eaton, W., Thara, R., Federman, B., Meton, B., Liang, K., 1995. Structure and course of positive and negative symptoms in schizophrenia. Arch. Gen. Psychiatry 52, 127-134. 
Elis, O., Caponigro, J.M., Kring, A.M., 2013. Psychosocial treatments for negative symptoms in schizophrenia: current practices and future directions. Clin. Psychol. Rev. 33, 914-928.

Ergül, C., Üçok, A., 2015. Negative symptom subgroups have different effects on the clinical course of schizophrenia after the first episode: a 24-month follow up study. Eur. Psychiatry 30, 14-19.

Evensen, J., Røssberg, J.I., Barder, H., Haahr, U., Hegelstad, W.T.V., Joa, I., Johannessen, J.O. Larsen, T.K., Melle, I., Opjordsmoen, S., Rund, B.R., Simonsen, E., Sundet, K., Vaglum, P., Friis, S., McGlashan, T., 2012. Apathy in first episode psychosis patients: a ten year longitudinal follow-up study. Schizophr. Res. 136, 19-24.

Fervaha, G., Agid, O., Takeuchi, H., Foussias, G., Remington, G., 2014a. Effect of antipsychotic medication on overall life satisfaction among individuals with chronic schizophrenia: findings from the NIMH CATIE study. Eur. Neuropsychopharmacol. 24, 1078-1085.

Fervaha, G., Foussias, G., Agid, O., Remington, G., 2014b. Motivational and neurocognitive deficits are central to the prediction of longitudinal functional outcome in schizophrenia. Acta Psychiatr. Scand. 1-10.

Foussias, G., Mann, S., Zakzanis, K.K., van Reekum, R., Agid, O., Remington, G., 2011. Prediction of longitudinal functional outcomes in schizophrenia: the impact of baseline motivational deficits. Schizophr. Res. 132, 24-27.

Foussias, G., Agid, O., Fervaha, G., Remington, G., 2014a. Negative symptoms of schizophrenia: clinical features, relevance to real world functioning and specificity versus other CNS disorders. Eur. Neuropsychopharmacol. 24, 693-709.

Foussias, G., Siddiqui, I., Fervaha, G., Agid, O., Remington, G., 2014b. Dissecting negative symptoms in schizophrenia: opportunities for translation into new treatments. J. Psychopharmacol. 1-11.

Galderisi, S., Bucci, P., Mucci, A., Kirkpatrick, B., Pini, S., Rossi, A., Vita, A., Maj, M., 2013. Categorical and dimensional approaches to negative symptoms of schizophrenia: focus on long-term stability and functional outcome. Schizophr. Res. 147, 157-162.

Galderisi, S., Rossi, A., Rocca, P., Bertolino, A., Mucci, A., Bucci, P., Rucci, P., Gibertoni, D., Aguglia, E., Amore, M., Bellomo, A., Biondi, M., Brugnoli, R., Dell'Osso, L., De Ronchi, D., Di Emidio, G., Di Giannantonio, M., Fagiolini, A., Marchesi, C., Monteleone, P. Oldani, L., Pinna, F., Roncone, R., Sacchetti, E., Santonastaso, P., Siracusano, A., Vita, A., Zeppegno, P., Maj, M., Chieffi, M., De Simone, S., De Riso, F., Giugliano, R., Piegari, G., Vignapiano, A., Caforio, G., Mancini, M., Colagiorgio, L., Porcelli, S., Salfi, R. Bianchini, O., Galluzzo, A., Barlati, S., Carpiniello, B., Fatteri, F., Di Santa Sofia, S.L. Cannav, D., Minutolo, G., Signorelli, M., Martinotti, G., Di Iorio, G., Acciavatti, T. Pallanti, S., Faravelli, C., Altamura, M., Stella, E., Marasco, D., Calcagno, P., Respino, M., Marozzi, V., Riccardi, I., Collazzoni, A., Stratta, P., Giusti, L., Ussorio, D., Delauretis, I., Serati, M., Caldiroli, A., Palazzo, C., Iasevoli, F., Gramaglia, C., Gili, S., Gattoni, E., Tenconi, E., Giannunzio, V., Monaco, F., De Panfilis, C., Camerlengo, A., Ossola, P., Landi, P., Rutigliano, G., Pergentini, I., Mauri, M., Di Fabio, F., Torti, C., Buzzanca, A., Comparelli, A., De Carolis, A., Corigliano, V., Di Lorenzo, G., Niolu, C., Troisi, A., Corrivetti, G., Pinto, G., Diasco, F., Goracci, A., Bolognesi, S., Borghini, E. Montemagni, C., Frieri, T., Birindelli, N., 2014. The influence of illness-related variables, personal resources and context-related factors on real-life functioning of people with schizophrenia. World Psychiatry 13:275-287. http://dx.doi.org/10.1002/ wps.20167.

Gardner, D.M., Murphy, A.L., O’Donnell, H., Centorrino, F., Baldessarini, R.J., 2010. International consensus study of antipsychotic dosing. Am J. Psychiatry. 167, 686-693.

Gould, F., McGuire, L.S., Durand, D., Sabbag, S., Larrauri, C., Patterson, T.L., Twamley, E.W. Harvey, P.D., 2015. Self assessment in schizophrenia: accuracy of evaluation of cognition and everyday functioning. Neuropsychology 29, 675-682.

Hartmann-Riemer, M.N., Hager, O.M., Kirschner, M., Bischof, M., Kluge, A., Seifritz, E. Kaiser, S., 2015. The association of neurocognitive impairment with diminished expression and apathy in schizophrenia. Schizophr. Res. 169, 427-432.

Herbener, E.S., Harrow, M., 2004. Are negative symptoms associated with functioning def icits in both schizophrenia and Nonschizophrenia patients? A 10-year longitudina analysis. Schizophr. Bull. 30, 813-826.

Hovington, C.L., Bodnar, M., Joober, R., Malla, A., Lepage, M., 2012. Identifying persistent negative symptoms in first episode psychosis. BMC Psychiatry 12, 224
Jones, B., Nagin, D., Roeder, K., 2001. A SAS procedure based on mixture models for estimating developmental trajectories. Sociol. Methods Res. 29, 374-393.

Kay, S.R., Fiszbein, A., Opler, L.A., 1987. The positive and negative syndrome scale (PANSS) for schizophrenia. Schizophr. Bull. 13, 261-276.

Kirkpatrick, B., 2014. Developing concepts in negative symptoms. J. Clin. Psychiatry 75, $3-7$

Korver, N., Quee, P.J., Boos, H.B.M., Simons, C.J.P., de Haan, L., GROUP Investigators, 2012. Genetic risk and outcome of psychosis (GROUP), a multi site longitudinal cohort study focused on gene-environment interaction: objectives, sample characteristics, recruitment and assessment methods. Int. J. Methods Psychiatr. Res. 21, 205-221.

Li, K.-H., Meng, X.-L., Raghunathan, T.E., Rubin, D.B., 1991. Significance levels from repeated p-values with multiply-imputed data. Stat. Sin. 1, 65-92.

Liemburg, E., Castelein, S., Stewart, R., van der Gaag, M., Aleman, A., Knegtering, H., 2013. Two subdomains of negative symptoms in psychotic disorders: established and confirmed in two large cohorts. J. Psychiatr. Res, 47, 718-725.

Little, R.J.A., Rubin, D.B., 2002. Statistical Analysis With Missing Data. John Wiley \& Sons, New York.

Messinger, J.W., Trémeau, F., Antonius, D., Mendelsohn, E., Prudent, V., Stanford, A.D., Malaspina, D., 2011. Avolition and expressive deficits capture negative symptom phenomenology: implications for DSM-5 and schizophrenia research. Clin. Psychol. Rev. 31, 161-168.

Milev, P., Ho, B.C., Arndt, S., Andreasen, N.C., 2005. Predictive values of neurocognition and negative symptoms on functional outcome in schizophrenia: a longitudinal first-episode study with 7-year follow-up. Am. J. Psychiatry 162, 495-506.

Niyonkuru, C., Wagner, A., Ozawa, H., Amin, K., Goyal, A., Fabio, A., 2013. Group-based trajectory analysis applications for prognostic biomarker model development in severe TBI: a practical example. J. Neurotrauma 30, 938-945.

Norman, R., Manchanda, R., Harricharan, R., Northcott, S., 2015. The course of negative symptoms over the first five years of treatment: data from an early intervention program for psychosis. Schizophr. Res. 169 (1-3), 412-417.

Rabinowitz, J., Berardo, C.G., Bugarski-Kirola, D., Marder, S., 2013. Association of prominent positive and prominent negative symptoms and functional health, well-being, healthcare-related quality of life and family burden: a CATIE analysis. Schizophr. Res. 150, 339-342.

Rocca, P., Montemagni, C., Zappia, S., Piterà, R., Sigaudo, M., Bogetto, F., 2014. Negative symptoms and everyday functioning in schizophrenia: a cross-sectional study in a real world-setting. Psychiatry Res. 218, 284-289.

Rubin, D., 1987. Multiple Imputation for Nonresponse in Surveys. J. Wiley \& Sons, New York.

SAS Institute Inc, 2013. SAS 9.4 Help and Documentation. SAS Institute Inc., Cary, NC

Savill, M., Banks, C., Khanom, H., Priebe, S., 2014. Do negative symptoms of schizophrenia change over time? A meta-analysis of longitudinal data. Psychol. Med. 1-15.

Staring, A.B.P., Ter Huurne, M.-A.B., van der Gaag, M., 2013. Cognitive behavioral therapy for negative symptoms (CBT-n) in psychotic disorders: a pilot study. J. Behav. Ther. Exp. Psychiatry 44, 300-306.

Stiekema, A.P.M., Liemburg, E.J., van der Meer, L., Castelein, S., Stewart, R., van Weeghel, J., Aleman, A., Bruggeman, R., 2016. Confirmatory factor analysis and differential relationships of the two subdomains of negative symptoms in chronically ill psychotic patients. PLoS One 11, e0149785.

Strauss, G.P., Horan, W., Kirkpatrick, B., Fischer, B.A., Keller, W.R., Miski, P., Buchanan, R.W., Green, M.F., Carpenter, W., 2013. Deconstructing negative symptoms of schizophrenia: avolition-apathy and diminished expression clusters predict clinical presentation and functional outcome. J. Psychiatr. Res. 47, 783-790.

Trompenaars, F.J., Masthoff, E.D., Van Heck, G.L., Hodiamont, P.P., De Vries, J., 2005. Content validity, construct validity, and reliability of the WHOQOL-Bref in a population of Dutch adult psychiatric outpatients. Qual. Life Res. 14, 151-160.

Turner, D., van der Gaag, M., Karyotaki, E., Cuijpers, P., 2014. Psychological interventions for psychosis. Am. J. Psychiatry 171, 523-538.

Ventura, J., Helleman, G., Thames, A.D., Koellner, V., Nuechterlein, K.H., 2009. Symptoms as mediators of the relationship between neurocognition and functional outcome in schizophrenia: a meta-analysis. Schizophr. Res. 113, 189-199. 